\title{
ANGIOMIXOMA PROFUNDO AGRESSIVO: relato de caso e revisão da literatura
}

Allyne Capanema GONÇALVES ${ }^{1}$

Marcus Vinícius Capanema GONÇALVES²

Nilton COSTA JUNIOR ${ }^{3}$

\begin{abstract}
${ }^{1}$ Acadêmica de Medicina na Universidade Federal de Minas Gerais (UFMG) - Belo Horizonte (MG), Brasil.
${ }^{2}$ Cirurgião Geral pelo Hospital das Clínicas da UFMG - Belo Horizonte (MG), Brasil.

${ }^{3}$ Cirurgião Geral pelo Hospital das Clínicas da UFMG - Belo Horizonte (MG), Brasil.
\end{abstract}

Recebido em: 23/05/2016 - Aprovado em: 13/08/2016 - Disponibilizado em: 18/12/2016

\begin{abstract}
RESUMO
Angiomixoma agressivo (AA) é uma neoplasia mesenquimalmixóide, de ocorrência rara. Acomete principalmente mulheres (acima de 90\%), em idade fértil. Possui crescimento lento, porém alta agressividade local. Raros casos de metástase são reportados. Exames de imagem como tomografia computadorizada (TC) e ressonância nuclear magnética (RNM), ajudam na delimitação e fornecem informações sobre a lesão, porém não fornecem um diagnóstico definitivo, que só é possível através de análise histopatológica da lesão. O tratamento é essencialmente cirúrgico, porém o tumor apresenta elevadas taxas de recidiva local, mesmo com margens livres de lesão.Apresentamos um relato de caso de uma paciente jovem, do sexo feminino, com AA em região inguinal, operada e acompanhada em nosso serviço - Hospital das Clínicas da UFMG.
\end{abstract}

Palavras-chave: Angiomixoma agressivo. Angiomixoma profundo agressivo. Neoplasia mesenquimalmixóide.

\section{ABSTRACT}

Aggressive angiomyxoma (AA) is a myxoid mesenchymal neoplasms, of rare occurrence. It mainly affects women (above $90 \%$ ), of childbearing age. It has slow growth, but high local aggressiveness. Rare cases of metastasis are reported. Imaging tests such as computed tomography (CT) and magnetic resonance imaging (MRI) help the delimitation and provide information about the injury, but did not provide a definitive diagnosis, which is possible only through histopathological analysis of the injury. Treatment is primarily surgical, but the tumor has high local recurrence rates, even free of injury margins. We present a case report of a young patient, female, with AA in inguinal region, operated and monitored in our service - Hospital das Clínicas .

Keywords: Aggressive angiomyxoma .Angiomyxoma aggressive deep . Neoplasia mesenchymal myxoid .

\section{RELATO DE CASO}

Paciente do sexo feminino, 17 anos, comparece com queixa de nodulação em região inguinal esquerda há 01 ano, indolor, de crescimento progressivo, não associado a sinais flogísticos locais ou piora à manobra de Valsalva. Refere emagrecimento de $06 \mathrm{~kg}$ no período. Sem outras queixas. Negou comorbidades ou uso regular de medicação.
Sem casos semelhantes ou história de neoplasia conhecidos na família.

Tomografia de pelve evidenciando lesão expansiva inguinal esquerda de margens bem definidas, sem sinais de invasão de estruturas adjacentes, medindo $54 \mathrm{~mm}$ em seu maior diâmetro. Lesão exibe intenso realce periférico pelo meio de contraste. 

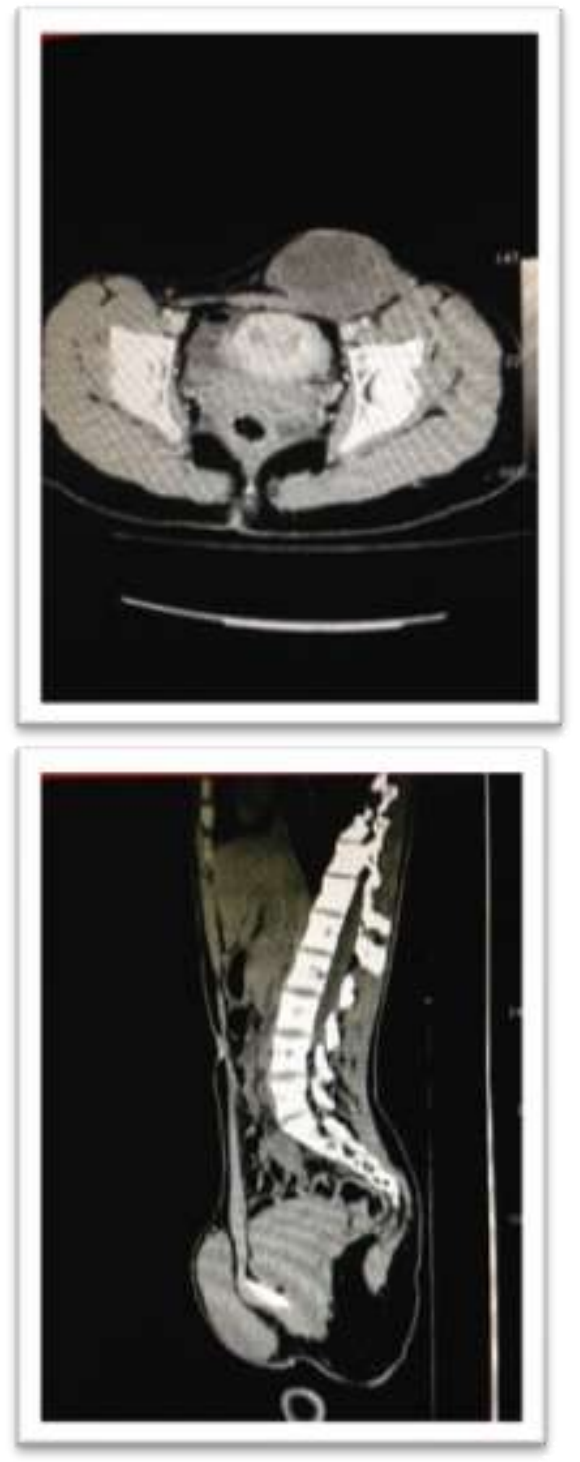

Figura 1: Imagens da lesão em TC

Ao exame físico, apresentava-se eutrófica, com nódulo em região inguinal esquerda, consistência amolecida, móvel, medindo aprox. $10 \mathrm{~cm}$, sem sinais flogísticos locais. Sem piora à manobra de Valsalva. Sem alterações de outros órgãos e sistemas.
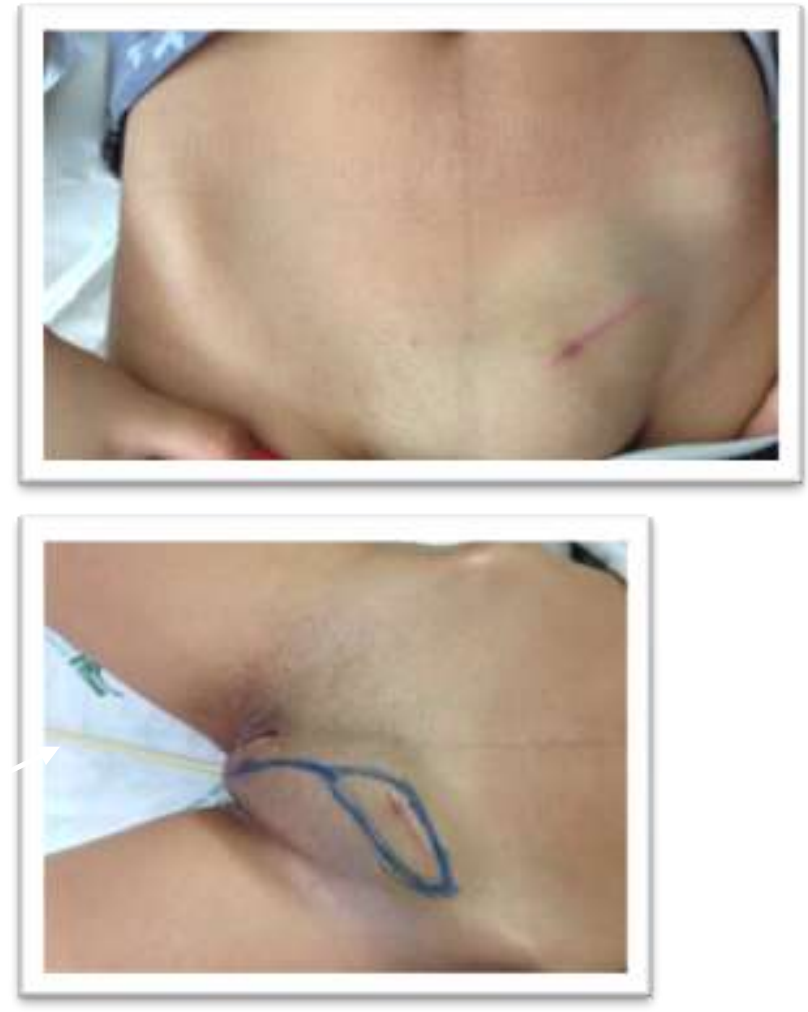

Figura 2: Imagens da paciente no pré-operatório.

Submetida à biópsia incisional em outro serviço, que evidenciou proliferação de células fusiformes estreladas, sem atipias significativas, dispostas frouxamente em meio a estroma mixóide e vasos sanguíneos, compatível com neoplasia mesenquimalmixóide, de baixo grau. Hipótese diagnóstica de Angiomixoma profundo agressivo.

Realizado tratamento cirúrgico por excisão completa da lesão por inguinotomia, que mostrou-se encapsulada, de consistência amolecida, sem invasão de estruturas adjacentes. Interior com material de consistência gelatinosa. 

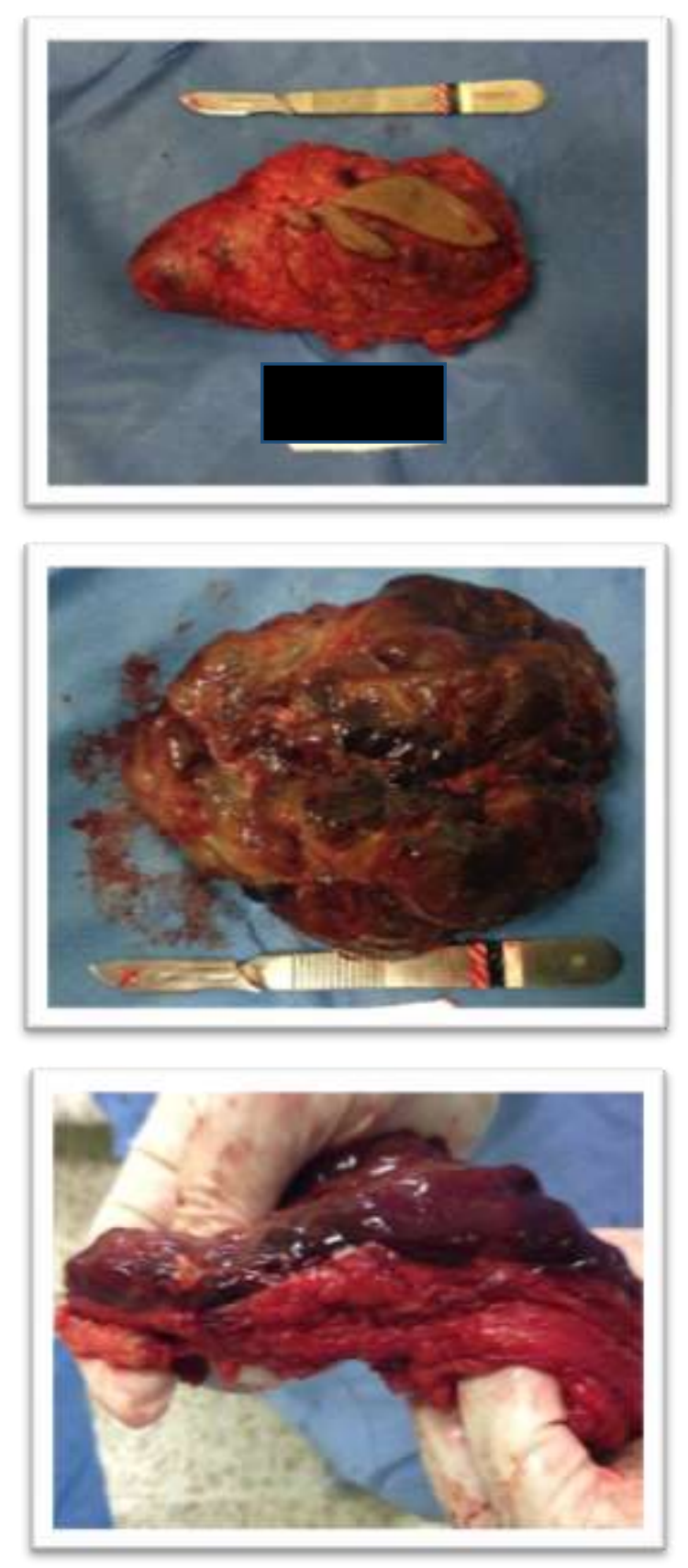

Figura 3: Imagens da peça cirúrgica, com cápsula intacta, e peça aberta.

Foi mantido um dreno portovac pela extensa excisão de tecido. A paciente evoluiu bem no pós operatório, sem intercorrências.

Durante acompanhamento ambulatorial, a paciente apresenta-se bem, sem sinais de recidiva tumoral em 01 ano de seguimento, até o momento.

\section{DISCUSSÃO}

Angiomixoma agressivo (AA) é uma neoplasia mesenquimalmixóide, de ocorrência rara, inicialmente descrito por Steeper e Rosai (1), em 1983, com aproximadamente 250 casos descritos na literatura (2). Acomete principalmente a região pélvica e períneo de pacientes quase exclusivamente do sexo feminino, jovens, em idade reprodutiva, com pico entre terceira e quarta décadas de vida $(2,3)$. No sexo masculino, o tumor aparece em lugares semelhantes, como escroto e região inguinal, porém acometendo homens mais velhos (2).

O tumor se apresenta inicialmente como um nódulo ou massa indolor em região pélvica/ períneo, assintomático, de crescimento muito lento, o que explica a demora do paciente em procurar atendimento médico (2). Pode apresentar sintomas de compressão de estruturas vizinhas, quando de grande tamanho. Pela ausência de sinais e sintomas típicos, e raridade da lesão, o diagnóstico definitivo normalmente é feito pela histologia após ressecção cirúrgica. Seu crescimento é predominantemente local, mas há alguns casos de metástases descritos na literatura. Apresenta altos índices de recorrência após tratamento cirúrgico, principalmente nos primeiros três anos, justificando o termo "agressivo" (3). 


\section{Propedêutica de imagem}

Os achados de imagem à tomografia podem variar, podendo consistir de massa pélvica/ perineal, de consistência sólida e infiltrativa, hipodensa em relação à musculatura, que tende a comprimir, mas não invadir, estruturas adjacentes; ou ser predominantemente cística, com componentes sólidos $(4,5)$.

Os achados na RM consistem em sinal isointenso ou hipointenso em imagens ponderadas em $\mathrm{T} 1$ e sinal hiperintenso em imagens ponderadas em $\mathrm{T} 2$. O hipersinal visto em T2 representa o volume de tecido mixomatoso e alto teor de água do tumor $(4,5)$. Um padrão espiralado de intensidade do sinal em T2 tem sido relatado como típico de angiomixoma agressivo. Esses tumores também mostram realce ao meio de contraste, o que reflete sua intensa vascularização. Nesse tipo de propedêutica, esses tumores tipicamente não mostram padrões infiltrativos e tendem a deslocar e comprimir as estruturas adjacentes, dependendo do tamanho da lesão (4).

Ao ultrassom, apresentam-se como imagem hipoecóica, característica de tecidos moles $(2,3)$.

Suas características inespecíficas à propedêutica de imagem não permitem a distinção do AA com outras neoplasias mesenquimais, como histiocitoma fibroso maligno mixóide e lipossarcomamixóide (3).
Os tumores recorrentes têm características semelhantes aos tumores primários (2).

\section{Achados histopatológicos}

Macroscopicamente, ele se apresenta como massa de consistência macia, parcialmente ou totalmente encapsulado. Ao corte, apresenta aspecto gelatinoso, de cor acinzentada e áreas de hemorragia e congestão. Têm um aspecto homogêneo, sem nodulações(2). Apresenta tamanho variado, desde $1 \mathrm{~cm}$ a $60 \mathrm{~cm}$ (5).

Histologicamente, revela lesão mesenquimalhipocelular, caracterizada por população esparsa de células fusiformes e estreladas, sem atipiascelulares ou mitóticas significativas, dispostas frouxamente em meio a estroma mixóide composto de fibras colágenas. A lesão normalmente apresenta grande número de vasos sanguíneos de variados calibres(2). É comum a infiltração em tecido moles, pela adesão em células musculares e nervosas (5).

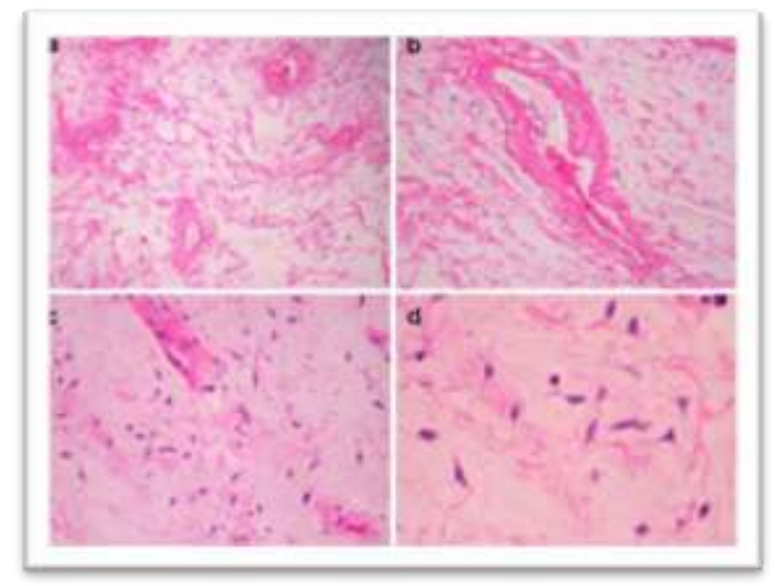

Figura 4: Imagens à microscopia óptica do tumor menor ao maior aumento.

Fonte: Aggressive angiomyxoma of the thigh, Skeletal Radiol, 2008 
À imunohistoquímica não existe um receptor específico para AA, porém apresenta um padrão característico de reações. Mostra receptores positivos para vimentina, e fracamente positivos paradesmina, actina, CD 34 e estrógeno e progesterona $(2,5)$.

\section{Características genéticas}

Foram reportadas mutações em casos de AA por translocação no cromossomo 12 , resultando em transcrição aberrante de proteínas da isoforma I-C, gene HMGIC, que possuem papel na transcrição do DNA $(2,6,7)$. No entanto, a baixa prevalência desse gene presente nos vasos sanguíneos, em comparação com sua alta prevalência nas células fusiformes estreladas, sugere que este último é o principal componente da neoplasia, sendo a angiogênese um aspecto secundário. $(2,7)$

\section{Tratamento}

Por ser um tumor localmente agressivo, excisão cirúrgica com amplas margens livres era inicialmente o tratamento de eleição, o que significava excisões extensas, com alta morbidade. No entanto, estudos recentes mostraram que pacientes submetidos à ressecção tumoral com margens livres ainda possuíam altas taxas de recidiva. As chances desses pacientes permanecerem sem doença, por um período de dez anos, não foi estatisticamente diferente daqueles com ressecção incompleta. Além disso, à exceção de raros casos reportados de metástase, o AA não apresenta uma ameaça a vida, e sua recidiva apresenta comportamento semelhante à neoplasia primária (8).

Ainda, como a fertilidade é um importante fator de risco, ressecções extensas e de alta morbidade não parecem benéficas em pacientes ainda jovens $(2,9)$.

Pela alta incidência de receptores para estrógeno e progesterona, terapias hormonais têm sido utilizadas como adjuvantes ao tratamento cirúrgico. Análogos de GnRH parecem ter efeito benéfico na diminuição do tamanho tumoral, principalmente no préoperatório (2). Embolização por angiografia também tem papel na diminuição tumoral. No entanto, não se mostrou eficaz na diminuição de recorrências (9).

Devido às baixas taxas de mitose no tumor, radioterapia e quimioterapia parecem ser de pouco valor (2).

\section{Acompanhamento}

As recidivas acontecem principalmente nos primeiros três anos de tratamento cirúrgico. No entanto, há relatos de recidiva após 14 anos. Portanto, o acompanhamento a longo prazo desses pacientes se faz necessário. $\mathrm{O}$ acompanhamento clínico parece ser suficiente, acompanhado de propedêutica de imagem, especialmente ressonância magnética, nos casos de suspeita de recidiva tumoral (2). 


\section{CONCLUSÃO}

Angiomixoma agressivo é um tumor raro, localmente agressivo, que acomete a região pélvica e períneo de mulheres em idade fértil. Apresenta alta incidência de recidivas, mesmo após excisões cirúrgicas extensas e margens livres de tumor. Seu diagnóstico é difícil pela raridade de ocorrência e ausência de sinais clínicos patognomônicos. No entanto, deve ser considerado em toda massa atípica em

\section{REFERÊNCIAS}

1. Steeper TA, Rosai J. Aggressive angiomyxoma of the female pelvis and perineum. Report of nine cases of a distinctive type of gynecologic soft-tissue neoplasm. Am J SurgPathol. 1983;7(5):463-75.

2. Haldar K; Martinek IE; Kehoe S. Aggressive angiomyxoma: a case series and literature review. Eur J SurgOncol 36(2010); $335-339$

3. Heffernan EJ; Hayes MM; Alkubaidan FO; Clarkson PW; Munk PL. Aggressive angiomyxoma of the thing. Skeletal Radiol (2008)37: 673-678

4. Castro CC; Campos ZM; Chiovatto RD; Busse PR et al. Angiomixoma agressivo pélvico residual. RadiolBras 2012 Ago, 45(2): 18

5. Sutton, BJ; Laudadio J. Aggressive angiomyxoma. Arch Pathol Lab Med Vol 136, 2012 pelve feminina. Poucas opções de tratamento estão disponíveis, sendo que tratamento cirúrgico com terapias adjuvantes parecem fornecer $\quad 0$ melhor resultado. Acompanhamento a longo prazo é essencial.

\section{TERMO DE CONSENTIMENTO}

Termo de consentimento por escrito foi obtido do paciente para publicação desse relato de caso.

6. Kondo T. Aggressive angiomyxoma in the inguinal region: a case report. Kondo Journal of Medical cases reports 2010 4: 396

7. Lourenço $\mathrm{C}$; Oliveira $\mathrm{N}$; Ramos $\mathrm{F}$, Ferreira I; Oliveira M. Aggressiveangiomyxomaofthe vagina: a case report. Ver BrasGinecolObstret 2013; 35(12): 575-82

8. Chan IM; Hon E. Aggressive angiomyxoma in females: is radical resection the only option? ActaObstetGynecolScand 2000; 79: 21620

9. Han-Geurts IJ; van Geel ANN et al. Aggressive angiomyxoma: multimodality treatments can avoid mutilating surgery. Eur J SurgOncol 2006 Dec; 32(10): 1217 21 